\title{
Pharmacological Studies on Marbofloxacin on Diarrheic Calves
}

\author{
El-sayed, M. G*, El- taysh*, A.R, Ayat k. Abd el-Rahman \\ Department of pharmacology Faculty of Vet. Med, Mansoura University.Egypt
}

\begin{abstract}
One -hundred diarrheic calves were used to differentiate various reasons for calf diarrhea by using rapid diagnostic kits which found the main causative agents for diarrhea occurrence are corona virus (28\%), Rota virus (25\%), Cryptosporidium (24\%) and E. coli (23\%), Respectively, in addition to study concurrent use of marbofloxacin (a third generation member of quinolone) in treatment of diarrheic calves infected with E. coli. Then twenty Holstein calves (0-10 days old) in special dairy farm at Damietta Governorate were isolated and divided into two groups, each group contain ten animals. First group was kept as control without any drug. The second group include ten diarrheic calves infected with E-coli and was injected by marbofloxacin intramuscularly $(2 \mathrm{mg} / \mathrm{kg} \mathrm{B}$. W) for 3 successive days. Results revealed a significant increase in total leukocytic count, lymphocyte count, monocyte count, eosinophil count, globulin, ALT, AST, ALP, creatinine and urea level. On other hand results recorded a significant decrease in total erythrocytic count, hemoglobin content, $\mathrm{PCV}, \mathrm{MCH}, \mathrm{MCHC}$, total protein, Albumin and thrombocyte count in marbofloxacin treated group compared to control one.
\end{abstract}

\section{INTRODUCTION}

Calf diarrhea has an opposing effect on calves' health status, permanency in the herd and productivity performance so it causes great economic losses. To increase the output for livestock unit without increasing its numbers, it is essential to categorize the etiological and disposing factors elaborated in calf diarrhea in order to develop preventive measures and decrease losses during the early months of life (Perez et al., 1998, Lorino et al., 2005).

Potential risk factors for neonatal calve diarrhea (NCD) can be categorized into farm-level factors related with animal husbandry, farm, management and infrastructure, and calf-level factors, for instance infection with specific enteropathogens, the status of calves' immune system, and its sex and breed (Bartels et al., 2010).

Diarrhea is a well-known clinical sign in neonatal animals. Its etiology is complex including management, environmental, nutritional, physiological variations and various of pathogens including bacteria, viruses, protozoa and intestinal parasites are labelled as important agents causing diarrhea (either separately or in combination) in buffalo calves (Prescott et al., 2008).

E. coli is one of the chief causative agents responsible for NCD and represents an economic challenge in livestock and dairy industries worldwide (Lorenz, I.et al., 2011).

Colibacilliosis in newborn (9-10 days' age) is regularly described by watery white or yellowish diarrhea, rapid onset, and high mortality. In affected calves, diarrhea usually begins within 36-72 hrs of birth, and affected calves die within 2-3 days (Radostits et al., 2007).
Antibiotic therapy is often used to treat different infectious diseases in animals including NCD. While this therapy may be related with a mortality rate reduction in some cases, the unselective use of antibiotics has been accompanied by an increase in bacterial resistance, generating important public health problems and economic losses in production industries in recent years (Cavaco, L.M. 2009.). The most commonly used antibiotics in animal's embrace $\beta$-lactams, aminoglycosides, fluoroquinolones, and tetracycline (Constable, P.D. 2004).

Fluoroquinolones reveal good activity against most gram(-ve ) bacteria, including E. coli, Enterobacter spps, Klebsiella spps, Pasteurella spps, Proteus spps, and Salmonella spps (Papich MG et al., 2001).

Marbofloxacin is a fluoroquinolone antibacterial drug developed for use in veterinary medicine SCHNEIDER et al., (2004), presenting a wide-spectrum activity against many pathogens of veterinary importance and is designated for the treatment of gastroenteritis and mastitis caused by sensitive strains of E.coli in calves and dairy cows correspondingly (TOUTAIN et al., 2002).

This work was planned to differentiate the different causes of diarrhea in calves and to evaluate the pharmacological effect of marbofloxacin ( $2 \mathrm{mg} / \mathrm{kg}$ BW intramuscularly for3 successive days) on hematology, kidney and liver functions in diarrheic calves with E. coli.

\section{MATERIALS AND METHODS}

\section{1-Drugs}

Product name: (Marbox $\left.{ }^{\circledR} 10 \%\right)$. 
Marbofloxacin is available as a $10 \%$ solution for injection under the trade name of Marbox ${ }^{\circledR}$, Obtained from (Ceva sante Animale, France).

\section{Dose}

The recommended dosage is $2 \mathrm{mg} / \mathrm{kg}$ in a single daily injection for 3 to 5 successive days by subcutaneous, intramuscular or intravenous routes in cattle, (Van huffel and Grandemange, E.2002).

\section{2-Experimental calves}

Our experiment was done on twenty Holstein calves (0-10 days old) in special dairy farm at Damietta Governorate. Calves were divided into two groups, each group ten animals. First group include ten diarrheic calves infected with $\mathrm{E}$-coli and was injected by marbofloxacin intramuscularly ( $2 \mathrm{mg} / \mathrm{kg}$ B.W) for 3 successive days.

The second group was kept as control group without any drug. The calves under our experiment were determined after long period of survey (from JAN to APRIL 2016) in different dairy farms at Dakahlia and Damietta Governorates, our survey were done on 100 diarrheic calves at different seasons at (0-10) days old age.

\section{3-Kits for diagnosis}

Kits were obtained from BIONOTE Company, Korea

\section{4-Experimental design}

Ten Holstein diarrheic calves infected with E. coli were injected intramuscularly in the thigh muscle by Marbofloxacin at $(2 \mathrm{mg} / \mathrm{kg}$ body weight) for 3 Successive days and other ten Holstein healthy calves were kept as control group without any drug.

\section{5-Sampling}

Two Blood samples (the first one for hematological studies and the second sample for serological studies) were collected from each experimental animal at zero day,3rd, 7th,14th day.

Blood samples were collected on Wassermann tube containing EDTA $(0.5 \mathrm{mg} / \mathrm{ml}$ blood) from jugular vein of all caves for hematological parameters studies (erythrocytic count, leukocytic count, $\mathrm{Hb}, \mathrm{PCV}, \mathrm{MCH}, \mathrm{MCHC}$ and thrombocyte count).

The second blood samples were collected in Wassermann tube without anticoagulant from jugular veins of all calves and permitted to clot at room temperature. The serum was separated by centrifugation at $3000 \mathrm{rpm}$ for 15 minutes. the sera were collected in $1.5 \mathrm{ml}$ Eppindorff tubes and kept frozen at $-20 \mathrm{c}$ for biochemical studies (total proteins, albumin, ALT, AST, ALP, Urea and creatinine) (Stofregen et al.,1997).

Kits for diagnosis of diarrheal cause: 6

\section{Principle}

The kit of Antigen Rapid BoviD-5 Ag Test has two letters on the device surface which are (T) the streak of test and (C) the streak of control and both streaks in the result hole are not detectable before mixing any samples. The streak of control is a reference line which indicates the test is performed. If the target is present in specimen, a purple test line would appear in the result windows

\section{7-Hematological studies}

The hematological studies such as estimaton of hemoglobin concentration $(\mathrm{Hb})$, total erythrocytic count (TEC), packed cell volume (PCV), mean corpuscular hemoglobin $(\mathrm{MCH})$, mean corpuscular hemoglobin concentration (MCHC), mean corpuscular volume (MCV), total leukocytic count (TLC) and differential leukocytic count (DLC) were carried out using fully Automated cell counter (Mindary BC2800).

\section{8-Serum Biochemical Analysis}

Biochemical serum analysis of total proteins, albumin, ALT, AST, ALP, Urea and creatinine were carried out using Automatic Biochemical Analyzer

Liver function tests:

Determination of Total Protein: according to (Doumas, 1975).

Determination of Albumin: according to (Doumas et al., 1981).

Serum globulin calculation: as described by (Doumas and Biggs, 1972).

Determination of serum Transaminases (ALT) and (AST): According to Reitman and Frankel (1957).

Determination of serum alkaline phosphatase (ALP): according to (Rosalki 1993).

\section{Kideny function tests}

Creatinine serum level determination: by the method of Zaloudek and Norris (1987).

Urea determination: by the method of (Patton and Croush, 1977).

9-Statistical analysis:

Data obtained in this study were statistically analyzed by one way (ANOVA), using SPSS computer program (Version. 20 ) and least significant difference ( LSD ) as described by Snedecor and Cochran ( $1981)$.

\section{RESULTS}

\section{1-Prevalance of different causes of calve scour:}

One hundred diarrheic calves at various farms at Dakhalia and Damietta Governorates were diagnosed by rapid diagnostic kits to identify causative agents of diarrhea as mentioned in Table (1)

2- The effect of intramuscular injection of marbofloxacin $(2 \mathrm{mg} / \mathrm{kg}$ body weight) for 3 continuous days on total erythrocytic count ,hemoglobin content and packed cell volume, on mean corpuscular volume, mean corpuscular hemoglobin and mean corpuscular hemoglobin concentration, total and differential leucocytic count and platelet count in calves as shown in table (2).

3- The effect of intramuscular injection of marbofloxacin $(2 \mathrm{mg} / \mathrm{kg}$ body weight) for 3 successive days on total protein, albumin, globulin alanine transaminase (ALT), aspartate transaminase (AST) and

Alkaline phosphatase (ALP), urea and creatinine in calves as shown in table (3). 
4- The effect of intramuscular injection of marbofloxacin $(2 \mathrm{mg} / \mathrm{kg}$ body weight) for 3 successive days on body weight in calves as shown in table (4).

Table (1): prevalence of different causes of calve scour at Damietta overnorates

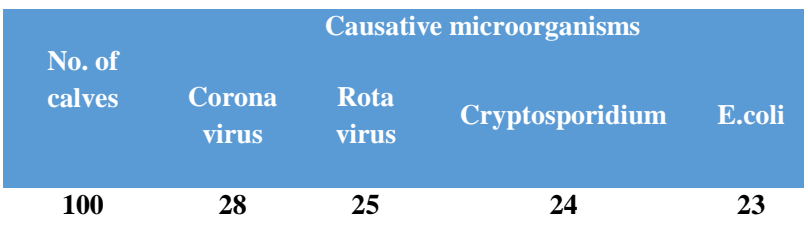

Table (3): The effect of intramuscular injection of marbofloxacin ( $2 \mathrm{mg} / \mathrm{kg}$ body weight) for 3 successive days on total protein, albumin, globulin alanine transaminase (ALT), aspartate transaminase (AST) and alkaline phosphatase (ALP), urea and creatinine in calves.

\begin{tabular}{|c|c|c|c|c|c|}
\hline Item & Group & Zero & $3^{\text {rd }}$ & $7^{\text {th }}$ & $14^{\text {th }}$ \\
\hline \multirow{2}{*}{$\begin{array}{l}\text { Total protein } \\
\text { (g/dl) }\end{array}$} & Control & $3.30 \pm 0.33$ & $2.40 \pm 0.26$ & $4.00 \pm 0.33$ & $4.40 \pm 0.22$ \\
\hline & Treated & $2.63 \pm 0.27^{*}$ & $2.31 \pm 0.14$ & $3.88 \pm 0.33$ & $4.14 \pm 0.26$ \\
\hline \multirow{2}{*}{ Albumin (g/dl) } & Control & $2.10 \pm 0.11$ & $1.99 \pm 0.12$ & $2.35 \pm 0.15$ & $3.10 \pm 0.17$ \\
\hline & Treated & $1.61 \pm 0.12^{*}$ & $1.58 \pm 0.12$ & $2.46 \pm 0.08$ & $2.84 \pm 0.15$ \\
\hline \multirow{2}{*}{ Globulin (g/dl) } & Control & $1.20 \pm 0.04$ & $0.41 \pm 0.02$ & $1.65 \pm 0.01$ & $1.30 \pm 0.03$ \\
\hline & Treated & $1.02 \pm 0.06$ & $0.73 \pm 0.01^{*}$ & $1.42 \pm 0.01$ & $1.30 \pm 0.02$ \\
\hline \multirow{2}{*}{ ALT (IU/L) } & Control & $6.50 \pm 0.45$ & $9.60 \pm 0.45$ & $6.90 \pm 0.62$ & $7.90 \pm 0.17$ \\
\hline & Treated & $7.80 \pm 0.84$ & $10.20 \pm 0.72 *$ & $7.70 \pm 0.39$ & $8.80 \pm 0.41$ \\
\hline \multirow{2}{*}{ AST (IU/L) } & Control & $7.10 \pm 0.50$ & $9.50 \pm 0.30$ & $9.50 \pm 0.77$ & $8.80 \pm 0.48$ \\
\hline & Treated & $11.10 \pm 0.50 *$ & $13.10 \pm 1.66^{*}$ & $9.90 \pm 0.37$ & $8.10 \pm 0.75$ \\
\hline \multirow{2}{*}{ ALP (IU/L) } & Control & $157.30 \pm 8.96$ & $161.80 \pm 8.86$ & $93.10 \pm 5.38$ & $135.60 \pm 5.70$ \\
\hline & Treated & $204.90 \pm 25.26^{*}$ & $159.40 \pm 16.38$ & $130.40 \pm 8.44^{*}$ & $209.30 \pm 19.91 *$ \\
\hline \multirow{2}{*}{ CR-s (gm/dl) } & Control & $0.33 \pm 0.04$ & $0.37 \pm 0.04$ & $0.33 \pm 0.03$ & $0.19 \pm 0.04$ \\
\hline & Treated & $0.86 \pm 0.03 *$ & $0.61 \pm 0.05^{*}$ & $0.57 \pm 0.03^{*}$ & $0.71 \pm 0.06^{*}$ \\
\hline \multirow{2}{*}{ urea (gm/dl) } & Control & $17.90 \pm 1.05$ & $22.00 \pm 1.23$ & $13.40 \pm 0.33$ & $11.20 \pm 0.35$ \\
\hline & Treated & $22.80 \pm 3.39 *$ & $26.50 \pm 2.57$ & $28.00 \pm 2.88^{*}$ & $17.30 \pm 1.19 *$ \\
\hline
\end{tabular}

*significant at $(p<0.01)$ 
Table (2): The effect of intramuscular injection of marbofloxacin ( $2 \mathrm{mg} / \mathrm{kg}$ body weight) for 3 continuous days on total erythrocytic count ,hemoglobin content and packed cell volume, on mean corpuscular volume, mean corpuscular hemoglobin and mean corpuscular hemoglobin concentration, total and differential leucocytic count and platelet count in calves.

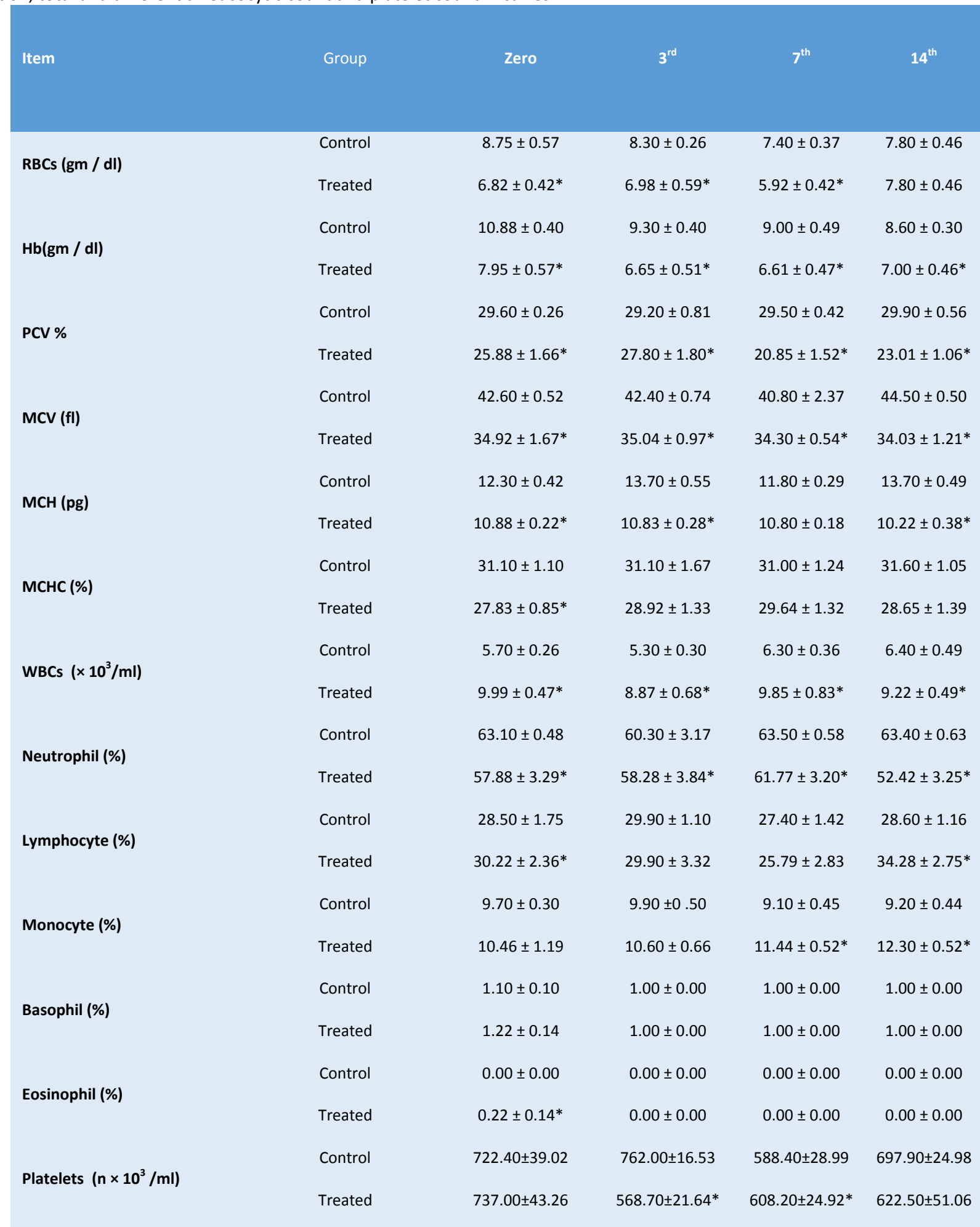

*significant at $(\mathrm{p}<0.01)$ 
Table (4): The effect of intramuscular injection of marbofloxacin ( $2 \mathrm{mg} / \mathrm{kg}$ body weight) for 3 successive days on body weight in calves.

\begin{tabular}{|crrrrr}
\hline Item & Group & Zero & $3^{\text {rd }}$ & $7^{\text {th }}$ & $14^{\text {th }}$ \\
& Control & $31.50 \pm 0.81$ & $33.40 \pm 0.73$ & $36.50 \pm 0.68$ & $40.00 \pm 0.69$ \\
Body weight $(\mathbf{k g})$ & & & $33.40 \pm 1.14$ & $37.44 \pm 1.19$ & $41.22 \pm 1.28$
\end{tabular}

\section{DISCUSSION}

Neonatal calf diarrhea is one of the most common diseases in young animals, producing giant economic and productivity losses to bovine industry worldwide. Calves are at highest danger of diarrhea with in the first month of life and the occurrence of diarrhea declines with age (Garcia et al., 2000; Cho and Yoon, 2014).

It's a complex disease, with various interrelated causes, agent, host, and environmental factors together explain scours, and these factors cooperate together over the course of time (David R. Smith, 2007).

The diarrheic calves appeared dull, depressed and lethargic with reduced appetite. The feces were semisolid to watery with aggressive odor, greenish to yellowish white in color and sometimes even stained with blood. Mild to moderate dehydration was found to be a constant feature in diarrheic calves. Rectal temperature, pulse and respiration rates were within the normal range (Ramkumar, 2012).

Our study conducted on 100 diarrheic calves at Dakahlia and Damietta Governorate (0-10 days old) to diagnose the main causative microorganism for calf scour. the study cleared that corona virus, rotavirus, cryptosporidium, E-coli are the main agent for incidence of diarrhea as (28 diarrheic calves) due to corona virus, (25 diarrheic calves) attributable to Rota virus, (24 diarrheic calves) caused by cryptosporidium and (23 diarrheic calves) by E-coli.

Our study documented a significant decrease in hemoglobin content and packed cell volume (PCV) in marbofloxacin treated group at zero, third, seventeenth and fourteenth post treatment compared to control group (Table 2).

Our result agree with Vipul (2017) who found significant decrease in The values of $\mathrm{HB}$ and PCV in post treatment with marbofloxacin administration alone $(5 \mathrm{mg} / \mathrm{kg}$ of body weight for 5 days) when compare to before treated values of the same parameters in piperine pretreated group $(p<0.05)$.
The decrease in PCV caused by decline TEC which attributed to many factor such as reduction of erythropoietin hormone. These result disagree with Ishak et al., (2008) who recorded higher PCV and red blood cell counts, and greater mean cell hemoglobin content in marbofloxacin-treated cats (2.75 mg/kg PO daily for14 days) infected with Mycoplasma haemofelis.

It also recorded decrease of total erythrocytic count (TEC) in marbofloxacin treated group at zero, third and seventeenth post treatment compared to control group (Table 2). This maintained by Shams, (2017) who approved decrease total erythrocytic count when administered marbofloxacin $(2 \mathrm{mg} / \mathrm{kg})$ with fluxinin meglumine $(2.2 \mathrm{mg} / \mathrm{kg})$ in mastitic cattle. Arafa et al. (2008) reported that significant decrease $(p<0.05)$ in total erythrocyte count, $\mathrm{HB}$ values, $\mathrm{MCH}$ and $\mathrm{MCHCH}$ values in diarrheic calves than values of healthy ones.

These data disagree with Modi et al., (2013) also detected no significant differences in RBCS and hemoglobin concentration after administration of marbofloxacin in sheep. Kamble et al., (2017) who observed no significant alterations in hematological parameters in sodium fluoride induced toxicity in Wister rat. Sadariya et al., (2010) reported that no significant changes in hematological paramters (Hemoglobin, $\mathrm{RBC}, \mathrm{WBC}, \mathrm{MCV}, \mathrm{MCH}, \mathrm{MCHC}, \mathrm{HCT}$ and $\mathrm{DLC})$ with marbofloxacin injection in rats.

The obtained data recorded also decrease of $\mathrm{MCH}$ in marbofloxacin treated group at zero third, and fourteenth post treatment compared to control group. Moreover, decrease of $\mathrm{MCHC}$ in marbofloxacin treated group at zero post treatment compared to control group (Table 2). Asati et al., (2008) studied on clinical signs, bacteriological examination, and haemato-biochemical changes in neonatal calf diarrhea due to colibacillosis and observed that the affected calves showed $\mathrm{MCV}$ and $\mathrm{MCH}$ increased and $\mathrm{MCHC}$ profiles were decreased during infection. This result maintained with $\mathrm{Al}$ Mayah and Al-Ahmed, (2005) who informed that enrofloxacin reduced the $\mathrm{MCV}, \mathrm{MCH}$ and $\mathrm{MCHC}$ values in 1-5 days old broilers. 
The diarrheic calves showed significant improvement and rapid recovery from these alterations after treatment by marbofloxacin.

The present data showed a significant increase of total leukocytic count in marbofloxacin treated group at zero, third, seventeenth and fourteenth post treatment compared to control group (Table 2). This may return to ability of fluoroquinolone to accumulate in macrophage and neutrophil, high percent of leucocyte indicate higher concentration of infected tissue than healthy one. Leukocytosis might have occurred due to normal reaction of body defense mechanism against infection and also due to dehydration and haemoconcentration (Kumar et al., 2010).

Asati et al., (2008) studied on hemato-biochemical changes in neonatal calf diarrhea due to $E$. coli infection and observed increase of total leukocyte count. Wadhwa et al., (2006) Examined 12 diarrheic calves aged between 7-20 days and animals were treated with $5 \mathrm{mg} / \mathrm{kg}$ enrofloxacin for 5 days then haematological examination revealed an increase in leukocyte count as compared with healthy calf.

While Ellakany et al., (2007) detected that 10-time dose of enrofloxacin decreased the total leukocyte in young broilers ( 6 days old), with no change in older animals, but decreased number of lymphocyte and increased number of heterophil were detected in adult one (34 days old).

Also the study recorded a significant decrease in neutrophil percent in marbofloxacin treated group at zero, third, seventeenth and fourteenth days' post treatment compared to control group (Table 2). As well, recorded a significant increase of lymphocyte percent in marbofloxacin treated group at zero and fourteenth days' post treatment compared to control group.

Asati et al., (2008) studied on hemato-biochemical changes in neonatal calf diarrhea due to colibacillosis and observed Blood picture of affected calves which showed lymphocytosis and neutropenia. Shams, (2017) also recorded asignificant increase in total lymphocyte percent in marbofloxacin $(2 \mathrm{mg} / \mathrm{kg})$ with tolfenamic acid $(2 \mathrm{mg} / \mathrm{kg})$ treated mastitic cattle.

The result mirrored a significant increase in monocyte percent in marbofloxacin treated group at seventeenth and fourteenth days post treatment compared to control group ,moreover an important increase in eosinophil percent at zero day post treatment compared to regulator group, in contrary with Vipul, (2017) who found significant decline in The values of eosinophil and monocyte in post treatment with marbofloxacin administration alone $(5 \mathrm{mg} / \mathrm{kg}$ of body weight for 5 days) when compare to before treated values of the same parameters in piperine pretreated group II $(p<0.05)$.
Also Shams, (2017) showed asignificant decrease in monocyte marbofloxacin $(2 \mathrm{mg} / \mathrm{kg})$ with fluxinin meglumine $(2.2 \mathrm{mg} / \mathrm{kg})$ in treated mastitic cattle due to fluxinin meglumine.

Our result evaluated a significant decrease in platelet count in marbofloxacin treated group at third day after treatment linked to control group, followed by a significant increase at seventh day post treatment compared to control group (Table 2).

Our result established with (Zhixin Lei et al., 2018) who recorded increase in WBC count and decrease in platelet in the 6 and $10 \mathrm{mg} / \mathrm{kg}$ treatment groups of peagle dog on day 14 and 40 compared to control group.

A significant decrease in total protein in marbofloxacin treated group at third day after treatment paralleled to control group, also a significant decrease in albumin level at third day after treatment associated to control group, plus to a significant increase in globin level at days' post treatment compared to control group were reported(Table3).

Keeping with the same ground our results supported with the results showed significant decreases in total proteins after 5 days of marbofloxacin treatment $(10 \mathrm{mg} / \mathrm{kg} \mathrm{B}$. W) given I/M in E. coli $\mathrm{O} 78$ experimentally infected quail compared to infected-non-treated group (EL-sheikh et al., 2007). These results are in reliable with the immunopharmacological effect of marbofloxacin in calves and attributed to the generalized inhibition effect on protein and B-cell activity (Zahra 2003). Also the effectiveness of marbofloxacin in the treatment of canine leishmaniosis confirmed by presenting hypoalbuminaemia with hyperglobulinaemia, in matching with an increase of the $A / G$ ratio joined with the clinical improvements (Kargin Kiral et al., 2004).

Results of the study are disagreeing by report of (Mahmood and Hussein, 2013) who found non-significant change in total protein, albumin and globulin following daily intramuscular administration marbofloxacin $(2 \mathrm{mg} / \mathrm{kg})$ and trovafloxacin (3 mg/kg) for five days in sheep. Sadariya et al., (2010) reported that no significant changes in total protein, albumin and globulin through marbofloxacin injection $(5 \mathrm{mg} / \mathrm{kg}$ ) at $24 \mathrm{~h}$ interval for 14 days in male and female Wister rats.

Alanine transaminase and aspartate transaminase are aminotransferases nonspecific intracellular enzymes which widely present in many organs but specially in liver. Their using is wide-ranging from broadcasting of liver disease to observing side effects of medication to determine reactions to treatment. The cellular damage and rupture of plasma membrane evoked the activities of these enzymes in serum (Wang et al., 2006). 
This work reflected a significant increase in serum alanine transaminase (ALT) level in marbofloxacin treated group at third day post treatment, Also detected a significant increase in serum aspartate transaminase (AST) level in marbofloxacin treated group at third and seventh days post treatment .Correspondingly these result mirrored a significant increase in alkaline phosphatase (ALP) level in marbofloxacin treated group at zero, seventh and fourteenth days post treatment compared to the control group (Table 3 ).

This conclusion is supported also by the findings reported by Coles (1974). Who mentioned that increased serum transaminase activities suggest hepatocellular damage.

Our result documented a significant increase in creatinine level in marbofloxacin treated group at all times after treatment compared with the regulator group (Table 3). Elevated level of creatinine in serum is known to reflect the state of glomerular filtration and indicate kidney disease (Coles, 1974).

A significant increase also detected in urea level at zero, seventh and fourteenth days after treatment with marbofloxacin comparing with the control group (Table 3).

The significant increase in serum urea nitrogen and creatinine in the present study was returned to dehydration as a consequence of diarrhea. The hypovolemia due to dehydration results in concentration of the plasma solutes with relation to increase in both parameters. the rise of urea concentrations is relatively more pronounced than that of creatinine concentrations in azotemia caused by dehydration (Stockham et al., 2008).

This agrees with Zhixin Lei.et. al., (2018) who found slightly increased ALP and blood urea nitrogen (BUN) were slightly increased in peagle dog after oral dosage of marbofloxacin at (6 and $10 \mathrm{mg} / \mathrm{kg}$ treatment), comparing with the regulator group.

In the parallel the obtained data supported by Ibrahim ElAshmawy et al., (2011) who recorded an important increase in the level of ALT, AST and alkaline phosphatase in the serum of treated rats with marbofloxacin I/M for 5 consecutive days at dosage level of $7.2 \mathrm{mg} / \mathrm{Kg} \mathrm{B.W}$ and14.4 mg / Kg B.W. respectively. Also, there was a significant increase in serum creatinine level in the all treated groups all over the periods of Experiment compared to control group. Also Lefebvre et al., (1998) recorded a significant increase in plasma creatinine and urea level after single intravenous injection and repeated administration for 8 days $(2 \mathrm{mg} / \mathrm{kg}$, once-a-day) of marbofloxacin in female peagle dog. The obtained results are confirmed by Sabbah, (2010) who recorded significant increase in serum enzymes levels following oral administration of quinolones (ciprofloxacin).
On other side This disagree with Patel et al., (2014) who reported that following single intravenous administration of marbofloxacin (2 $\mathrm{mg} / \mathrm{kg})$ the values of alanine aminotransferase was significantly reduced after drug administration in sheep but within the normal clinical range. Bhavsar et al., (2004) who determined Other fluoroquinolones like ciprofloxacin when given repeated in calves at intra muscular dose in calves did not cause any significant alteration in the values of (ALT, AST, ALP, creatinine and urea level).

Our work revealed a non -significant increase in calves' body weight in marbofloxacin treated calves at zero, third, seventh, and fourteenth days' post treatment compared to the control group(Table4). This maintained by administration of ciprofloxacin to rat at low and a high dose for a short duration of 7 days and a long duration of 30 days, did not lead to any significant alteration in the body weight of rats at both durations (DK.M.Priyadharshini, et al., 2013).

\section{Conclusion}

From this study it was concluded that repeated intramuscular administration of marbofloxacin at the dose rate $(2 \mathrm{mg} / \mathrm{kg} \mathrm{BW})$ in diarrheic calves was found safe and have highly significant effect on hematological and Biochemical parameters of diarrheic calves and consider a corner of stone in treatment and control of diarrhea caused by bacterial infection.

\section{REFERENCES}

Patel, H. B.; Mody, S. K.; Ratn Deep Singh.; Raval, S. H. and Patel, H. A. (2014): Haematology and plasma biochemistry influenced by administration of marbofloxacin in sheep: Safety impact. Journal of Veterinary Pharmacology and Toxicology, 13(2):156-160.

Ahmed s. Mousa, ibrahim m. El-ashmawy and abdel-salam f. El-sawy.2011 adverse effects of marbofloxacin in male rats issn 110-2047 alex. J. Vet. Science 2011 vol. 33 no.1: (13-21).

Ellakany HF., Abu El-Azm IM, Bekhit AA., Shehawy MM., 2007: Studies on the effects of enrofloxacin overdose on different health parameters in boiler chickens. BS. Vet. Med. J., 5th Scientific Conference 176-186.

Stockham SL, Scott MA (2002) Fundaments of veterinary clinical pathology, 1st edn. lowa State, Ames, pp 21-30.

Modi, C.M.; Mody, S.K. and Patel, H.B. (2013). Hematological alteration induced after intramuscular administration of long acting moxifloxacin in sheep. Biochem. Physiol., 2(2):111

Sabbah, E. A. (2010): Some pharmacological studies on ciprofloxacin. A Master Thesis Presented to Pharmacology Department, Faculty of Veterinary Medicine, Alexandria University.

Bhavsar, S. K.; Verma, M. P. and Thaker, A. M. (2004): Pharmacokinetics, tissue concentration and safety of multiple dose Intravenous administration of ciprofloxacin in cow calves. Journal of Veterinary Pharmacology and Toxicology, 3(1):27-34.

Perez E, Kummeling A, Janssen C, Alvarado R, Caballero M, Donado $P$ and Dwinger RH. 1998. Infectious agents associated with diarrhoea of calves in the Canton of Tilaran, Costa Rica. Preventive Veterinary Medicine 33 (1-4): 195-205

Lorenz 1.2006. Diarrhoea of the young calves: An update. World Buiatrics CongressNice, Franc. 
DK.M.Priyadharshini., Asst Professor, PSG CAS Coimbatore., and Dr.G.Vanithakumari. onowitz GR, Mandell GL.: Beta-lactam antibiotics. N Engl J Med 988; 318: 419-26.

Radostits, O.M.; Gay, C.C.; Hinchcliff, K.W. and Constable, P.D. (2007): Veterinary Medicine, 10th edition. PP. 847-888. Saunders, Philadelphia.

Sadariya k.A., A.K Gothi S.D. patel ,S.K. Bhavsar and A.M Thaker (2010): safety of Moxifloxacin following repeated intramuscular administration in wistar rats , veterinary World ,2010,Vol.3 (10):449-452.

Shams.M.M.I.(2017): Use of some antibiotics and anti-inflammatory in control of mastitis in cattle. master degree. Mansoura University.

Vipul B. C, Chirag M. Modi, Urvesh D. Patel, Harshad B. Patel, Vinay A. Kalaria, Dhaval T. Fefar Dixita H. Bhadarka, Shivani L. Solanki and Shaul R. Ahmed: Safety profile of marbofloxacin following repeated intramuscular administration alone and piperine pretreated ratsAnnals of Phytomedicine 6(2): 88-92.,2017.

Prescott, J.F., Baggot, J.D., Walker, R.D. (2000): Antimicrobial Therapy in Veterinary Medicine, 3rd Ed., lowa State University Press, Ames., pp. 191-228.

Mahmood and Hussein, A. (2013): Pharmacokinetics, pharmacodynamics and safety of marbofloxacin and trovafloxacin in sheep. Thesis at University of Queensland.

Papich MG, Riviere JE.: Fluoroquinolone antimicrobial drugs. In: Adams HR, editor. Veterinary Pharmacology and Therapeutics, 8th ed. Ames: lowa State University Press, 2001. p. 898-912.

Schneider M, Vallé $M$, Woehrlé $F$, et al.: Pharmacokinetics of marbofloxacin in lactating cows after repeated intramuscular administrations and pharmacodynamics against mastitis isolated strains. J Dairy Sci 2004; 87:202-11.

tOUTAIN P.L., DEL CASTILLO J.R.E., BOUSQUETMELOU A.: The pharmacokinetic-pharmacodynamic approach to a rational dosage regimen for antibiotics. Res. Vet. Sci., 2002, 73, 105-114.

Grandemange E, Gunst S, Woehrle F, et al. Field evaluation of the efficacy of Marbocy ${ }^{\circledR} 2 \%$ in the treatment of infectious arthritis in calves. Irish Veterinary Journal 2002; 55:237-40.

Doumas b.t.; baysa d.d.; carller,r.j; peler t.and schaffer,r (1981): determination of serum albumin .clinical chem 12;1642.

Doumas b. And biggs, h. (1972): Determination of serum globulin in standard methods of clinical chemistry vol .7editedby cooper.newyork,academic press.

Doumas, b (1975): Colometric determination of total protein in serum or plasma. clin.chem ,21:(8),249-254.

REITMAN, S AND FRANKKEL S. (1957): Acolorimeteric Method For The Determination Of Serum Glutamic Oxaloacetic And Glutamic Pyruvic Ansaminases.56american Journal Of Clinical Pathology ; 28:(1),56-63.

ROSALKI, S. (1993): QUALITATIVE DETERMINATION OF ALKALINE PHOSPHATASE CLIN CHEM ,39(4),648-652.

Coles, E. H. (1974): Veterinary Clinical Pathology. Pp. 213, W. B. Saunders Company, Philadelphia, London, Toronto.

ZaLoudek,C.and NorrIS H.J(1987): Mesenchymal Tumors OF the uterus .BlauStein'S pathology of the female Gential Tract Springer New York .373-408.

Patton,C.J and Croush S.R(1977): Enzymatic determination of urea. AnaL. Chem,49:466-469.

Snedecor, G And Cochran,W. (1981): statisTItical method .7 th .lowa State Univ .press. lowa .USA.

A.M. Ishak, K.L. Dowers, M.T. Cavanaugh, C.C. Powell, J.R. Hawley, S.V. Radecki, and M.R. Lappin(2008): Marbofloxacin for the Treatment of Experimentally Induced Mycop.

Al-Mayah AS.,Al-Ahmed JA., 2005: Influence of antibiotic treatment on hematological aspect in chicken. Int. J. Poult. Sci., 4, 323-325. lasma haemofelis Infection in Cats. J Vet Intern Med 2008; 22:288-292.

Arafa, M.M., Sanaa, A. Abdou and Sarfenase- S. Abd El-Ghany 2008. Biochemical, hematological and histopathological studies in fattening buffaloes with dietary diarrhoea in Sharkia. Egypt. J. Comp. Path. Clinic. Path., 21(2): 42-58.

Kamble, A. U.; Sawarkar, A. R.; Borkar, S. D. and Jangde, C. R. (2017): Effect of Moringa oleifera Lam. on haematological and parameters in sodium flouride induced toxicity in wistar rats. Ann. histopathological Phytomed., 6(1):57-62.

Asati CK, Roy S and Roy M. 2008. Haemato-biochemical study and diagnosis in calves. Intas-Polivet. 9(2): 245-248.

Kaur K, Randhawa SS and Chhabra S. 2006. Haemato-biochemical profile of diarrhoeic dairy calves affected with colibacillosis. Indian Journal of Veterinary Medicine. 26 (I): 9-n.

A.M. Ishak, K.L. Dowers, M.T. Cavanaugh, C.C. Powell, J.R. Hawley, S.V. Radecki, and M.R. Lappin(2008): Marbofloxacin for the Treatment of Experimentally Induced Mycop.

Zhixin Lei, Qianying Liu, Bing Yang, Haseeb Khaliq, Saeed Ahmed, Bowen Fan, Jiyue Cao and Qigai He (2018): Evaluation of Marbofloxacin in Beagle Dogs After Oral Dosing: Preclinical Safety Evaluation and Comparative Pharmacokinetics of Two Different Tablets.

Kargin Kiral, F., Seyrek, K., Pasa, S., Ertabaklar, H., Unsal, C., 2004: Some haematological, biochemical and electrophoretic findings in dogs with visceral leishmaniosis. Rev. Méd. Vet. 155, 226-229.

Zahra, A.A. and Abd El-Azem, A.M. (2003): Immunopharmacological effects of marbofloxacin in calves. Zag. Vet. J. 31, 1: pp.188-19.

Modi FD (2009) Studies on pharmacokinetics of moxifloxacin in sheep. Sardarkrushinar Dantiwada Agriculture University. Sardarkrushinar. India

Lefebvre, H.P., Schneider, M., Dupouy, V., Laroute, V., Costes, G., Delesalle, L. \& Toutain, P.L. (1998) Effect of experimental renal impairment on disposition of marbofloxacin and its metabolites in the dog. Journal of Veterinary Pharmacology and Therapeutics, 21, 453-461. 